\title{
Activation cross section and isomeric cross section ratio for the ${ }^{76} \mathrm{Ge}(\mathrm{n}, 2 \mathrm{n}){ }^{75 m, g} \mathrm{Ge}$ process
}

\author{
Junhua Luo ${ }^{1,2, a}$, Li Jiang ${ }^{3}$, and Xinxing Wang ${ }^{2}$ \\ 1 Institute of New Energy, Hexi University, Zhangye 734000, China \\ 2 School of Physics and Electromechanical Engineering, Hexi University, Zhangye 734000, China \\ 3 Institute of Nuclear Physics and Chemistry, Chinese Academy of Engineering Physics, Mianyang 621900, China
}

Received: 3 December 2017 / Revised: 15 March 2018

Published online: 26 April 2018

(c) The Author(s) 2018. This article is published with open access at Springerlink.com

Communicated by T. Motobayashi

\begin{abstract}
We measured neutron-induced reaction cross sections for the ${ }^{76} \mathrm{Ge}(\mathrm{n}, 2 \mathrm{n}){ }^{75 \mathrm{~m}, \mathrm{~g}} \mathrm{Ge}$ reactions and their isomeric cross section ratios $\sigma_{m} / \sigma_{g}$ at three neutron energies between 13 and $15 \mathrm{MeV}$ by an activation and off-line $\gamma$-ray spectrometric technique using the K-400 Neutron Generator at the Chinese Academy of Engineering Physics (CAEP). Ge samples and $\mathrm{Nb}$ monitor foils were activated together to determine the reaction cross section and the incident neutron flux. The monoenergetic neutron beams were formed via the ${ }^{3} \mathrm{H}(d, n){ }^{4} \mathrm{He}$ reaction. The pure cross section of the ground state was derived from the absolute cross section of the metastable state and the residual nuclear decay analysis. The cross sections were also calculated using the nuclear model code TALYS-1.8 with different level density options at neutron energies varying from the reaction threshold to $20 \mathrm{MeV}$. Results are discussed and compared with the corresponding literature data.
\end{abstract}

\section{Introduction}

Activation cross sections of neutron threshold reactions on medium mass nuclei are of considerable interest for testing nuclear models. Furthermore, the data for potential first wall constituents of a fusion reactor are of practical importance, especially for estimating nuclear heating, nuclear transmutation, and radiation damage effects [1]. A lot of experimental data on neutron induced cross sections for fusion reactor technology applications have been reported and great efforts have been devoted to compilations and evaluations $[2,3]$. We chose to study the neutron-induced reaction cross sections of germanium-76 mainly for four reasons. First, the germanium is an important semi-conducting material for the nuclear technology and integrated circuits; second, the ${ }^{76} \mathrm{Ge}$ nucleus lies between the magic numbers of 28 and 50; shape coexistence plays a prominent role in its structure [4], and ${ }^{76} \mathrm{Ge}$ may be a rare example of a nucleus exhibiting rigid triaxial deformation in its low-lying states $[5,6]$; third, the germanium-75 isomeric pair is an example of the isomeric pair type in which the half-life of the metastable state is shorter than that of the ground state and decays almost entirely by isomeric transition (see fig. 1); fourth, although there are enough data for metastable cross sections for the ${ }^{76} \mathrm{Ge}(\mathrm{n}, 2 \mathrm{n}){ }^{75 \mathrm{~m}} \mathrm{Ge}$ reactions in the energy

\footnotetext{
a e-mail: luojh71@163.com
}

range from 13 to $15 \mathrm{MeV}$ [7-14], only three direct measurements for the ground state cross section $\sigma_{g}$ have been performed separately $[7,9,14]$. The experimental and theoretical data for the ${ }^{76} \mathrm{Ge}(\mathrm{n}, 2 \mathrm{n}){ }^{75 \mathrm{~g}} \mathrm{Ge}$ reaction cross section are inconsistent. In the energy region around $14 \mathrm{MeV}$, the experimental cross sections $[7,9,14]$ are clustered around $550 \mathrm{mb}$, while the results of TALYS are centered around $300 \mathrm{mb}$.

Therefore, we aimed to measure the pure ground state cross section $\sigma_{g}$ directly by means of the analysis methods of residual nuclear decay [15-17] and to compare the experimental results to those obtained by the statistical model calculation.

\section{Experimental}

\subsection{Samples and irradiations}

Two disks, about 0.1 and $0.19 \mathrm{~cm}$ in thickness and $20 \mathrm{~mm}$ in diameter, were formed by pressing approximately 1.7 and $3.2 \mathrm{~g}$ of $\mathrm{Ge}(99.99 \%$ pure) powder (natural isotopic composition) at $980 \mathrm{MPa}$ to form a pellet. The samples were irradiated near the target and sandwiched between two Nb foils (99.99\% pure, $0.12 \mathrm{~mm}$ thick) with the same diameter which were used to monitor the neutron fluence via the ${ }^{93} \mathrm{Nb}(\mathrm{n}, 2 \mathrm{n})^{92 \mathrm{~m}} \mathrm{Nb}$ reaction. 


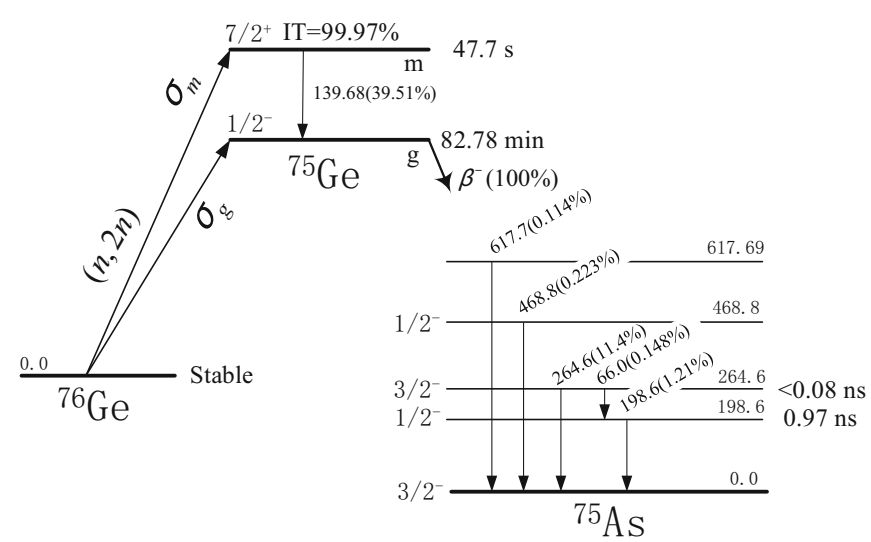

Fig. 1. Metastable and ground state formation in the reaction ${ }^{76} \mathrm{Ge}(\mathrm{n}, 2 \mathrm{n})^{75 \mathrm{~m}, \mathrm{~g}} \mathrm{Ge}[18]$. All energies are in $\mathrm{keV}$.

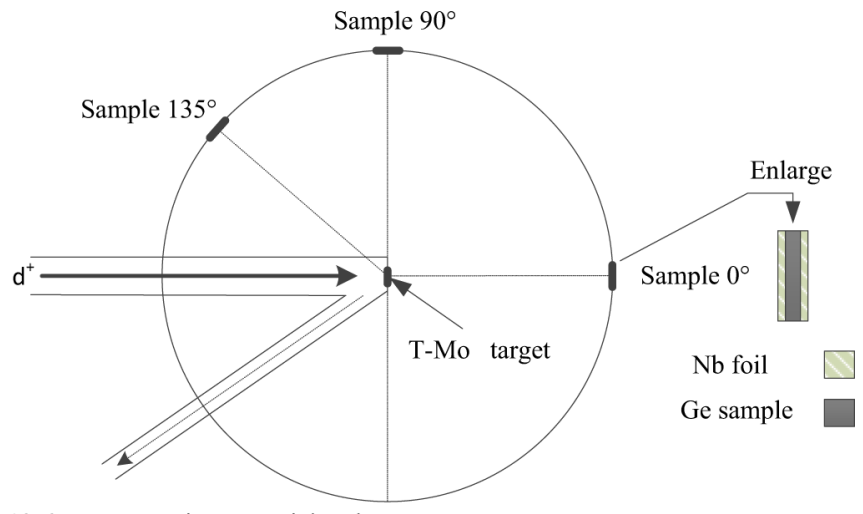

$135^{\circ}$ accompanying $\alpha$ particle tube

Fig. 2. Sketch of the experimental geometry. The Au-Si surface barrier detector used in $\alpha$-particle tube was positioned at $135^{\circ}$ and $110 \mathrm{~cm}$ from the target.

Irradiation of the samples was carried out at the K-400 Neutron Generator at the Chinese Academy of Engineering Physics (CAEP) and lasted approximately 3 minutes with a neutron yield $(3-4) \times 10^{10} \mathrm{n} / \mathrm{s}$ in $4 \pi$ solid angle. Neutrons were produced by the $\mathrm{T}(\mathrm{d}, \mathrm{n})^{4} \mathrm{He}$ reaction with an effective deuteron beam energy of $135 \mathrm{keV}$, beam current of $240 \mu \mathrm{A}$, and the diameter of the deuteron beam spot was under $0.6 \mathrm{~cm}$. The groups of samples were placed at $0^{\circ}, 90^{\circ}$ and $135^{\circ}$ relative to the beam direction and centered a $0.566 \mathrm{mg} / \mathrm{cm}^{2}$ thick tritium-molybdenum (T-Mo) target at a distance of $\sim 50 \mathrm{~mm}$. In order to avoid the deposition of deuterium in the target, the new T-Mo target is used. The diameter of the active zone of the T-Mo target is $1.2 \mathrm{~cm}$. The sample positions in the experiment are shown in fig. 2. In order to avoid the effect of low energy neutrons, samples were wrapped in cadmium foil. During irradiation, the neutron flux was monitored by accompanying $\alpha$-particles so that corrections could be made for small variations of the yield. Cross sections for the ${ }^{93} \mathrm{Nb}(\mathrm{n}, 2 \mathrm{n})^{92 \mathrm{~m}} \mathrm{Nb}$ monitor reaction were taken from [19].

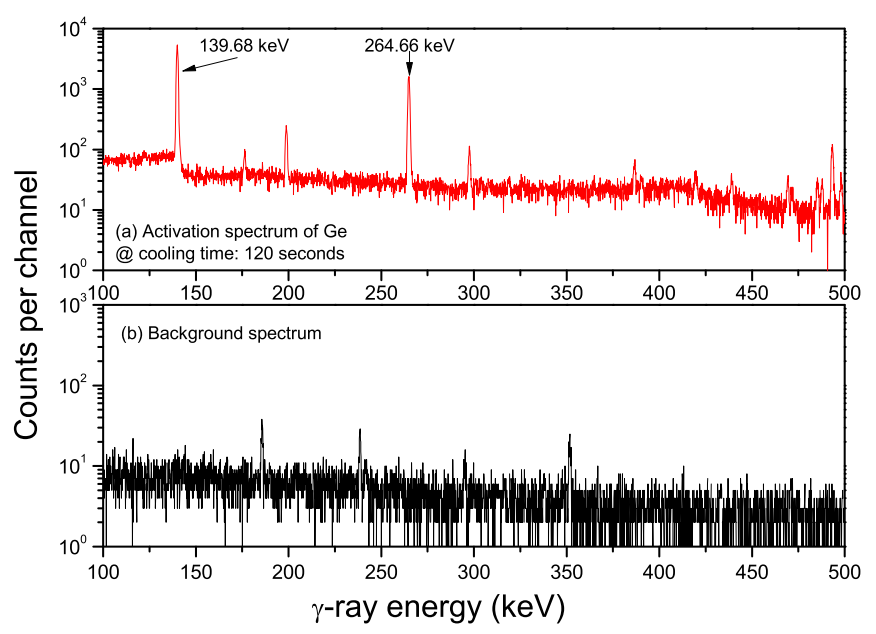

Fig. 3. (a) The $\gamma$-ray spectrum of germanium about 2 minutes after the end of irradiation; (b) the background spectrum.

\subsection{Measurement of radioactivity}

High-resolution gamma-ray spectroscopy was applied to the activated disks. The measurements were carried out using low-background high-purity germanium (HPGe) detector (ORTEC, model GEM 60P, crystal diameter $70.1 \mathrm{~mm}$, crystal length $72.3 \mathrm{~mm}$ ) with a relative efficiency of $\sim 68 \%$ and an energy resolution of $1.69 \mathrm{keV}$ at $1.332 \mathrm{MeV}$ for ${ }^{60} \mathrm{Co}$. The distance from sample to detector was $2.0 \mathrm{~cm}$. To avoid excessive death time, the sample was cooled for 2 minutes after irradiation. Figure 3 shows the typical spectra acquired from the Ge samples during the measurement of the isomeric and ground state, where the $\gamma$-rays of interest have been marked. The $\gamma$-ray intensities and half-lives used in the analysis are summarized in table 1 [18]. The detector was pre-calibrated for energy and efficiency by using the standard gamma ray sources ${ }^{54} \mathrm{Mn}$, ${ }^{57} \mathrm{Co},{ }^{60} \mathrm{Co},{ }^{109} \mathrm{Cd},{ }^{133} \mathrm{Ba},{ }^{137} \mathrm{Cs},{ }^{152} \mathrm{Eu},{ }^{241} \mathrm{Am}$ and ${ }^{226} \mathrm{Ra}$.

\subsection{Calculation of cross sections and their uncertainties}

The cross sections were calculated by the following formula $[16,17]$ :

$$
\sigma_{x}=\frac{\left[S \varepsilon I_{\gamma} \eta K M D\right]_{0}}{\left[S \varepsilon I_{\gamma} \eta K M D\right]_{x}} \cdot \frac{[\lambda A F C]_{x}}{[\lambda A F C]_{0}} \sigma_{0},
$$

where the subscript 0 represents the term corresponding to the monitor reaction and subscript $x$ corresponds to the measured reaction; $\varepsilon$ is the full-energy peak efficiency of the measured characteristic gamma-ray; $I \gamma$ is the gammaray intensity; $\eta$ is the abundance of the target nuclide; $M$ is the mass of the sample; $D=e^{-\lambda t_{1}}-e^{-\lambda\left(t_{1}+t_{2}\right)}$ is the counting collection factor; $S=1-e^{-\lambda T}$ is the growth factor of the product nuclide, $T$ is the total irradiation time; $t_{1}$ is the total cool time and $t_{2}$ is the total measurement time; $A$ is the atomic weight; $C$ is the measured full energy peak area; $\lambda$ is the decay constant; $K$ is the neutron 
Table 1. Neutron induced nuclear reactions on germanium and niobium and decay data of associated activation products (taken from [18]).

\begin{tabular}{|c|c|c|c|c|c|c|}
\hline Reaction & $\begin{array}{c}\text { Abundance } \\
\text { of target } \\
\text { isotope (\%) }\end{array}$ & $\begin{array}{c}\text { Half-life of } \\
\text { product }\end{array}$ & $\begin{array}{c}E \text {-threshold } \\
(\mathrm{MeV})\end{array}$ & $\begin{array}{c}\text { Mode of } \\
\text { decay (\%) }\end{array}$ & $\begin{array}{c}E_{\gamma} \\
(\mathrm{keV})\end{array}$ & $I_{\gamma}(\%)$ \\
\hline${ }^{76} \mathrm{Ge}(\mathrm{n}, 2 \mathrm{n}){ }^{75 \mathrm{~m}} \mathrm{Ge}$ & $7.73_{12}$ & $47.7_{5} \mathrm{~s}$ & 9.694 & $\mathrm{IT}(99.97)$ & 139.68 & 39.51 \\
\hline${ }^{76} \mathrm{Ge}(\mathrm{n}, 2 \mathrm{n})^{75 \mathrm{~g}} \mathrm{Ge}$ & $7.73_{12}$ & $82.78_{4} \mathrm{~m}$ & 9.552 & $\beta(100)$ & 264.6 & 11.4 \\
\hline${ }^{93} \mathrm{Nb}(\mathrm{n}, 2 \mathrm{n}){ }^{92 \mathrm{~m}} \mathrm{Nb}$ & 100 & $10.15_{2} \mathrm{~d}$ & 8.972 & $\mathrm{EC}(100)$ & 934.44 & 99.15 \\
\hline
\end{tabular}

Table 2. Correction factors for the self-absorption of the sample at a given gamma-ray energy.

\begin{tabular}{|c|c|c|c|c|c|}
\hline \multirow{2}{*}{$\begin{array}{c}\text { Gamma-energy } \\
(\mathrm{keV})\end{array}$} & \multirow{2}{*}{$\mu / \rho\left(\mathrm{cm}^{2} / \mathrm{g}\right)$} & \multirow{2}{*}{$\mu\left(\mathrm{cm}^{-1}\right)$} & \multicolumn{2}{|r|}{ Samples } & \multirow{2}{*}{ Correction factors } \\
\hline & & & no. & thickness $h(\mathrm{~cm})$ & \\
\hline \multirow[t]{2}{*}{139.68} & 0.3122 & 1.662 & 1 & 0.1863 & 1.163 \\
\hline & & & 2 & 0.0948 & 1.081 \\
\hline \multirow[t]{2}{*}{264.6} & 0.1319 & 0.702 & 1 & 0.1863 & 1.067 \\
\hline & & & 2 & 0.0948 & 1.034 \\
\hline
\end{tabular}

fluence fluctuation factor:

$$
K=\left[\sum_{i}^{L} \Phi_{i}\left(1-e^{-\lambda \Delta t_{i}}\right) e^{-\lambda T_{i}}\right] / \Phi S,
$$

where $L$ is the number of time intervals into which the irradiation time is divided; $\Delta t_{i}$ is the duration of the $i$-th time interval; $T_{i}$ is the time interval from the end of the $i$-th interval to the end of irradiation; $\Phi_{i}$ is the neutron flux averaged over the sample during $\Delta t_{i} ; \Phi$ is the neutron flux averaged over the sample during the total irradiation time $T . F$ is the total correction factor of the activity:

$$
F=f_{s} \times f_{g}
$$

where $f_{s}$ and $f_{g}$ are correction factors for the selfabsorption of the sample at a given gamma-ray energy and the counting geometry, respectively. The gamma ray attenuation correction factor in the Ge pellet, $f_{s}$ and the geometry correction, $f_{g}$ were calculated by eqs. (3) and (4),

$$
\begin{aligned}
& f_{s}=\frac{\mu h}{1-\exp (-\mu h)}, \\
& f_{g}=\frac{(D+h / 2)^{2}}{D^{2}},
\end{aligned}
$$

where $\mu$ (in $\left.\mathrm{cm}^{-1}\right)$ is the linear attenuation coefficient in Ge for gamma rays at each of the photon energies, $E$ (see table 2), $h$ (in $\mathrm{cm}$ ) is the thickness of the sample and $D$ (in $\mathrm{cm}$ ) is the distance from the measured sample to the surface of the Ge crystal. The mass attenuation coefficients, $\mu / \rho$ for the germanium, which are 0.3122 and $0.1319 \mathrm{~cm}^{2} / \mathrm{g}$ at gamma-ray energies of 139.68 and $264.6 \mathrm{keV}$ respectively, were obtained by interpolating values from the literature [20]. The linear attenua-

\begin{tabular}{|c|c|c|}
\hline $\begin{array}{l}\text { Irradiating } \\
\rightarrow t\end{array}$ & $\begin{array}{r}\text { Cooling } \\
\rightarrow t^{\prime}\end{array}$ & $\begin{array}{l}\text { Measuring } \\
\rightarrow t^{\prime \prime}\end{array}$ \\
\hline$-T$ & $-t_{1}$ & $=t_{2}=$ \\
\hline
\end{tabular}
tion coefficients in Ge were then calculated according to $\rho=5.323 \mathrm{~g} / \mathrm{cm}^{3}$. The correction factors at 139.68 and $264.6 \mathrm{keV}$ gamma-rays are given in table 2 .
Fig. 4. Sketch map of the time during which the sample is irradiated, cooled, and measured.

While calculating the cross sections of the ${ }^{76} \mathrm{Ge}(\mathrm{n}, 2 \mathrm{n})$ ${ }^{75 \mathrm{~g}} \mathrm{Ge}$ reaction, $C_{x}$ in (1) should be the result of the measured full-energy peak area (at $264.6 \mathrm{keV} \gamma$-ray) minus the contribution from ${ }^{75 m} \mathrm{Ge}$ via ${ }^{75 m} \mathrm{Ge} \stackrel{\text { IT (99.97\%) }}{\longrightarrow}{ }^{75 \mathrm{~g}} \mathrm{Ge}$ (counting $C_{m g}^{\prime}$ ). According to the regulation of growth and decay of artificial radioactive nuclide we can deduce a formula to calculate the number of the daughter nucleus ${ }^{75 \mathrm{~m}} \mathrm{Ge}$ at any moment $t$ during the irradiation (see fig. 4 ) as follows:

$$
N_{m}(t)=\frac{N \phi_{0} \sigma_{m}}{\lambda_{m}}\left(1-e^{-\lambda_{m} t}\right)
$$

where $\sigma_{m}$ is the cross sections for formation of the metastable, $\lambda_{m}$ is the decay constant of this state, $\phi_{0}$ is the mean neutron flux in neutrons $/ \mathrm{cm}^{2} / \mathrm{sec}$, and $N$ is the number of target nuclei.

At any moment $t$ during the irradiation, the number of ${ }^{75 \mathrm{~g}} \mathrm{Ge}$ from the ${ }^{75 \mathrm{~m}} \mathrm{Ge} \rightarrow{ }^{75 \mathrm{~g}} \mathrm{Ge}$ procedure meets the following equation:

$$
\frac{\mathrm{d} N_{g}(t)}{\mathrm{d} t}=P_{m g} \lambda_{m} N_{m}(t)-\lambda_{g} N_{g}(t)
$$

where $P_{m g}$ is the fraction of disintegrations of the metastable state that produces ground state nuclides (branching ratio), $\lambda_{g}$ is the decay constant of ${ }^{75 \mathrm{~g}} \mathrm{Ge}$. 
Using eqs. (5) and (6) and the initial condition: $t=0$, $N_{g}(0)=0$, and working out $N_{g}(t)$,

$$
\begin{aligned}
N_{g}(t)= & N \phi_{0} \sigma_{m} P_{m g}\left[\left(\frac{1}{\lambda_{g}}-\frac{1}{\lambda_{g}-\lambda_{m}} e^{-\lambda_{m} t}\right)\right. \\
& \left.-\left(\frac{1}{\lambda_{g}}-\frac{1}{\lambda_{g}-\lambda_{m}}\right) e^{-\lambda_{g} t}\right] .
\end{aligned}
$$

At the moment of the end of the irradiation $(t=T)$, the numbers of ${ }^{75 \mathrm{~m}} \mathrm{Ge}$ and ${ }^{75 \mathrm{~g}} \mathrm{Ge}$ from ${ }^{75 \mathrm{~m}} \mathrm{Ge} \rightarrow{ }^{75 \mathrm{~g}} \mathrm{Ge}$ are $N_{m}(T)$ and $N_{g}(T)$, respectively, which can be obtained by using eqs. (5) and (7).

At any moment $t^{\prime}$ after the irradiation, the number of ${ }^{75 \mathrm{~m}} \mathrm{Ge}$ is

$$
N_{m}\left(t^{\prime}\right)=N_{m}(T) e^{-\lambda_{m} t^{\prime}}=\frac{N \phi_{0} \sigma_{m}}{\lambda_{m}}\left(1-e^{-\lambda_{m} T}\right) e^{-\lambda_{m} t^{\prime}}
$$

At any moment after the irradiation $t^{\prime}$, the number of ${ }^{75} \mathrm{~g}$ Ge from ${ }^{75 \mathrm{~m}} \mathrm{Ge} \rightarrow{ }^{75 \mathrm{~g}} \mathrm{Ge}$ meets eq. (6). Using eqs. (6) and (8) and the initial condition $t^{\prime}=0, N_{g}(0)=N_{g}(T)$ (the number of ${ }^{75 \mathrm{~g}} \mathrm{Ge}$ from ${ }^{75 \mathrm{~m}} \mathrm{Ge} \rightarrow{ }^{75 \mathrm{~g}} \mathrm{Ge}$ is equal at the end of the irradiation and the start of cooling) and working out $N_{g}\left(t^{\prime}\right)$,

$$
\begin{aligned}
N_{g}\left(t^{\prime}\right)= & \frac{N \phi_{0} \sigma_{m} P_{m g}}{\lambda_{g}-\lambda_{m}}\left[\left(1-e^{-\lambda_{m} T}\right) e^{-\lambda_{m} t^{\prime}}\right. \\
& \left.-\frac{\lambda_{m}}{\lambda_{g}}\left(1-e^{-\lambda_{g} T}\right) e^{-\lambda_{g} t^{\prime}}\right] .
\end{aligned}
$$

Let $t^{\prime}$ in eqs. (8) and (9) equal $t^{\prime \prime}+t_{1} \cdot t_{1}$ is the time interval from the end of the irradiation to the start of counting. We can obtain the number of ${ }^{75 m} \mathrm{Ge}$ at any moment $t^{\prime \prime}$ after beginning to detect the characteristic $\gamma$ ray of ${ }^{75 m} \mathrm{Ge}$

$$
N_{m}\left(t^{\prime \prime}\right)=\frac{N \phi_{0} \sigma_{m}}{\lambda_{m}}\left(1-e^{-\lambda_{m} T}\right) e^{-\lambda_{m} t_{1}} e^{-\lambda_{m} t^{\prime \prime}}
$$

and the number of ${ }^{75 \mathrm{~g}} \mathrm{Ge}$ from the ${ }^{75 \mathrm{~m}} \mathrm{Ge} \rightarrow{ }^{75 \mathrm{~g}} \mathrm{Ge}$ procedure at any moment $t^{\prime \prime}$ after beginning to detect the characteristic $\gamma$ ray of ${ }^{75 g} \mathrm{Ge}$

$$
\begin{aligned}
N_{g}\left(t^{\prime \prime}\right)= & \frac{N \phi_{0} \sigma_{m} P_{m g}}{\lambda_{g}-\lambda_{m}}\left[\left(1-e^{-\lambda_{m} T}\right) e^{-\lambda_{m} t_{1}} e^{-\lambda_{m} t^{\prime \prime}}\right. \\
& \left.-\frac{\lambda_{m}}{\lambda_{g}}\left(1-e^{-\lambda_{g} T}\right) e^{-\lambda_{g} t_{1}} e^{-\lambda_{g} t^{\prime \prime}}\right]
\end{aligned}
$$

During the period $t_{2}$ of detecting the characteristic $\gamma$ ray, the full-energy peak (FEP) counts $C_{m}^{\prime}$ of the characteristic $\gamma$ ray of ${ }^{75 m} \mathrm{Ge}$ and $C_{m g}^{\prime}$ of the characteristic $\gamma$ ray of ${ }^{75 \mathrm{~g}} \mathrm{Ge}$ from the ${ }^{75 \mathrm{~m}} \mathrm{Ge} \rightarrow{ }^{75 \mathrm{~g}} \mathrm{Ge}$ procedure are

$$
\begin{aligned}
& C_{m}^{\prime}=\int_{0}^{t_{2}} \lambda_{m} I_{m} \varepsilon_{m} N_{m}\left(t^{\prime \prime}\right) \mathrm{d} t^{\prime \prime}= \\
& \frac{I_{m} \varepsilon_{m} N \phi_{0} \sigma_{m}}{\lambda_{m}}\left[\left(1-e^{-\lambda_{m} T}\right) e^{-\lambda_{m} t_{1}}\left(1-e^{-\lambda_{m} t_{2}}\right)\right] \\
& C_{m g}^{\prime}=\int_{0}^{t_{2}} \lambda_{g} I_{g} \varepsilon_{g} N_{g}\left(t^{\prime \prime}\right) \mathrm{d} t^{\prime \prime}= \\
& \frac{I_{g} \varepsilon_{g} N \phi_{0} \sigma_{m} P_{m g}}{\lambda_{g}-\lambda_{m}}\left[\frac{\lambda_{g}}{\lambda_{m}}\left(1-e^{-\lambda_{m} T}\right) e^{-\lambda_{m} t_{1}}\left(1-e^{-\lambda_{m} t_{2}}\right)\right. \\
& \left.-\frac{\lambda_{m}}{\lambda_{g}}\left(1-e^{-\lambda_{g} T}\right) e^{-\lambda_{g} t_{1}}\left(1-e^{-\lambda_{g} t_{2}}\right)\right]
\end{aligned}
$$

Using eqs. (12) and (13), $C_{m g}^{\prime}$ can be written as

$$
C_{m g}^{\prime}=\frac{P_{m g} \varepsilon_{g} I_{g} C_{m}^{\prime}\left(\lambda_{g}^{2} S_{m} D_{m}-\lambda_{m}^{2} S_{g} D_{g}\right)}{\left(\lambda_{g}-\lambda_{m}\right) S_{m} D_{m} I_{m} \varepsilon_{m} \lambda_{g} K_{m}},
$$

where $S_{m}=1-e^{-\lambda_{m} T}$ and $S_{g}=1-e^{-\lambda_{g} T} ; I_{m}$ and $I_{g}$ are the gamma ray intensities of the measured metastable and ground state, respectively; $\varepsilon_{m}$ and $\varepsilon_{g}$ are the full-energy peak efficiencies of the characteristic gamma-rays of the measured metastable and ground state, respectively; $K_{m}$ is neutron fluence fluctuation factor of the metastable state; $D_{m}$ and $D_{g}$ can be written as

$D_{m}=e^{-\lambda_{m} t_{1}}-e^{-\lambda_{m}\left(t_{1}+t_{2}\right)}, \quad D_{g}=e^{-\lambda_{g} t_{1}}-e^{-\lambda_{g}\left(t_{1}+t_{2}\right)}$

\section{Nuclear model calculations}

The excitation functions for the reactions were studied theoretically using the numerical nuclear model code TALYS-1.8 [21]. The theoretical calculations were computed using the default parameter values and only changing the choice of the level density models. The level density parameters were calculated using the six different choices of level density models available in TALYS-1.8. The six level density models are given in table 3 .

\section{Discussions}

The cross sections measured in this work are presented in table 4 . The uncertainty analysis was carried out using the quadrature method [22]. The principal sources of uncertainty and their estimated values are given in table 5 . The total uncertainty lies between 4.5 and $8.7 \%$. The small contribution to the gamma ray activity of products from the ${ }^{74} \mathrm{Ge}(\mathrm{n}, \gamma)$ reaction could be ignored because of the very small cross section of the $(n, \gamma)$ reaction in the region of $14 \mathrm{MeV}$. Furthermore, samples were wrapped in a cadmium foil in order to reduce the contribution of thermal and epithermal effects. For the ${ }^{76} \mathrm{Ge}(\mathrm{n}, 2 \mathrm{n})^{75 \mathrm{~m}, \mathrm{~g}} \mathrm{Ge}$ reactions the cross sections slightly increase with the increasing neutron energy. The various reactions are discussed below. 
Table 3. The six different level density models.

\begin{tabular}{|l|l|}
\hline Level density model & Describes \\
\hline ldmodel 1 & $\begin{array}{l}\text { the constant temperature and Fermi gas model, where the } \\
\text { constant temperature model is used in the low excitation region } \\
\text { and the Fermi-gas model in the high excitation energy region. } \\
\text { The transition energy is around the neutron separation energy. }\end{array}$ \\
\hline ldmodel 2 & the back-shifted Fermi gas model. \\
\hline ldmodel 3 & the generalized superfluid model. \\
\hline ldmodel 4 & $\begin{array}{l}\text { composed of microscopic level densities (Skyrme force) from } \\
\text { Goriely's tables [23]. }\end{array}$ \\
\hline ldmodel 5 & $\begin{array}{l}\text { composed of microscopic level densities (Skyrme force) from } \\
\text { Hilaire's combinatorial tables [23]. }\end{array}$ \\
\hline ldmodel 6 & $\begin{array}{l}\text { microscopic level densities (temperature dependent HFB, Gogny force) } \\
\text { from Hilaire's combinatorial tables [23]. }\end{array}$ \\
\hline
\end{tabular}

Table 4. Summary of cross section measurements.

\begin{tabular}{|c|c|c|c|}
\hline \multirow{2}{*}{ Reaction } & \multicolumn{3}{|c|}{ Cross sections (in mb) at various neutron energies (in MeV) } \\
\cline { 2 - 4 } & $13.5 \pm 0.2$ & $14.1 \pm 0.2$ & $14.8 \pm 0.2$ \\
\hline${ }^{76} \mathrm{Ge}(\mathrm{n}, 2 \mathrm{n})^{75 \mathrm{~m}} \mathrm{Ge}$ & $870 \pm 39$ & $899 \pm 41$ & $910 \pm 44$ \\
\hline${ }^{76} \mathrm{Ge}(\mathrm{n}, 2 \mathrm{n})^{75 \mathrm{~g}} \mathrm{Ge}$ & $376 \pm 31$ & $380 \pm 33$ & $381 \pm 30$ \\
\hline${ }^{76} \mathrm{Ge}(\mathrm{n}, 2 \mathrm{n}){ }^{75} \mathrm{Ge}$ & $1246 \pm 70$ & $1279 \pm 74$ & $1291 \pm 74$ \\
\hline${ }^{93} \mathrm{Nb}(\mathrm{n}, 2 \mathrm{n})^{92 \mathrm{~m}} \mathrm{Nb}$ & $457.9 \pm 6.8[19]$ & $459.8 \pm 6.8[19]$ & $459.7 \pm 5.0[19]$ \\
\hline
\end{tabular}

Table 5. Principal sources of uncertainty and their estimated values in cross section measurements.

\begin{tabular}{|l|l|}
\hline Source of uncertainty & Uncertainty \% \\
\hline counting statistics & $0.5-3.2$ \\
\hline standard cross sections & $1.1-1.5$ \\
\hline isotopic abundance & 1.6 \\
\hline detector efficiency & $2.0-3.0$ \\
\hline weight of samples & 0.1 \\
\hline self-absorption of gamma-ray & $\sim 0.5$ \\
\hline relative gamma-ray intensity & $\sim 1.0$ \\
\hline half-life & $0.05-1.1$ \\
\hline $\begin{array}{l}\text { uncertainties of irradiation, } \\
\text { cooling and measuring times }\end{array}$ & $0.1-0.5$ \\
\hline total uncertainty & $4.5-8.7$ \\
\hline
\end{tabular}

\section{1 ${ }^{76} \mathrm{Ge}(\mathrm{n}, 2 \mathrm{n})^{75 \mathrm{~m}} \mathrm{Ge}$ reaction}

In the present work, an intensity of $I_{\gamma}=39.51 \%$ of the $139.68 \mathrm{keV}$ gamma-ray emitted in the decay of ${ }^{75 \mathrm{~m}} \mathrm{Ge}$ was used to deduce the value of the ${ }^{76} \mathrm{Ge}(\mathrm{n}, 2 \mathrm{n}){ }^{75 \mathrm{~m}} \mathrm{Ge}$ reaction cross section. Vanska and Rieppo [9] and Hlavac et al. [12] used $I_{\gamma}=34 \%$, Kasugai et al. [10] used $I_{\gamma}=38.8 \%$ for the same ray $(139.68 \mathrm{keV})$ (see table 6 ). Thus, these data are normalized with respect to the latest $\gamma$-ray branching of $39.51 \%$ [18]. For this reaction, it's threshold energy is $9.694 \mathrm{MeV}$. In order to avoid the effect of low-energy neutrons, the near threshold ${ }^{93} \mathrm{Nb}(\mathrm{n}, 2 \mathrm{n})^{92 \mathrm{~m}} \mathrm{Nb}\left(E_{t h}=\right.$ $8.972 \mathrm{MeV}$ ) monitor reaction was selected. Whereas, Vanska and Rieppo [9], Kasugai et al. [10], Mangal and Gill [11], Hlavac et al. [12], and Attar et al. [14] used the lower threshold ${ }^{27} \mathrm{Al}(\mathrm{n}, \mathrm{p}){ }^{27} \mathrm{Mg}\left(E_{t h}=1.896 \mathrm{MeV}\right)$ and Dzysiuk et al. [13] used ${ }^{27} \mathrm{Al}(\mathrm{n}, \alpha)^{24} \mathrm{Na}\left(E_{t h}=3.249 \mathrm{MeV}\right)$ monitor reactions (see table 6 ). Our results are plotted in fig. 5 along with all the other data [7-14]. In the energy region between 13 and $14 \mathrm{MeV}$ our values are in agreement with those of Bormann et al. [8] within their experimental uncertainties. At $14.8 \mathrm{MeV}$, present data is in agreement with the results of Kasugai et al. [10], Hlavac et al. [12] and Attar et al. [14] within the experimental uncertainties. The shapes of the excitation curves of the TALYS-1.8 calculation also exhibit a trend similar to Bormann et al. [8], Kasugai et al. [10], Attar et al. [14], and the present data set. Between 13 and $15 \mathrm{MeV}$ the TALYS-1.8 calculations with ldmodels 1,5 , and 6 agree very well with our measured data within the reported data uncertainties.

\section{$4.2{ }^{76} \mathrm{Ge}(\mathrm{n}, 2 \mathrm{n}){ }^{75 \mathrm{~g}} \mathrm{Ge}$ reaction}

Concerning the ${ }^{76} \mathrm{Ge}(\mathrm{n}, 2 \mathrm{n})^{75 \mathrm{~g}} \mathrm{Ge}$ reaction, there are three earlier measurements that can be found in the litera- 
Table 6. Summary of ${ }^{76} \mathrm{Ge}(\mathrm{n}, 2 \mathrm{n})$ reaction cross sections from previous measurements.

\begin{tabular}{|c|c|c|c|c|c|}
\hline Reaction & Method & Decay data & Detector & Monitor reaction & Reference \\
\hline \multirow[t]{8}{*}{${ }^{76} \mathrm{Ge}(\mathrm{n}, 2 \mathrm{n}){ }^{75 \mathrm{~m}} \mathrm{Ge}$} & activation & no information & $\mathrm{GeLi}$ & ${ }^{63} \mathrm{Cu}(\mathrm{n}, 2 \mathrm{n}){ }^{62} \mathrm{Cu}$ & ref. [7] \\
\hline & activation & $T_{1 / 2}=48.2 \mathrm{~s}$ & $\mathrm{NaI}$ & No information & ref. [8] \\
\hline & activation & $T_{1 / 2}=49 \mathrm{~s}, E_{\gamma}=136 \mathrm{keV}, I_{\gamma}=34 \%$ & GeLi & ${ }^{27} \mathrm{Al}(\mathrm{n}, \mathrm{p}){ }^{27} \mathrm{Mg}$ & ref. [9] \\
\hline & activation & $T_{1 / 2}=47.7 \mathrm{~s}, E_{\gamma}=139.5 \mathrm{keV}, I_{\gamma}=38.8 \%$ & HPGe & ${ }^{27} \mathrm{Al}(\mathrm{n}, \mathrm{p}){ }^{27} \mathrm{Mg}$ & ref. $[10]$ \\
\hline & activation & $T_{1 / 2}=48 \mathrm{~s}$ & $\mathrm{NaI}$ & ${ }^{27} \mathrm{Al}(\mathrm{n}, \mathrm{p}){ }^{27} \mathrm{Mg}$ & ref. [11] \\
\hline & activation & $T_{1 / 2}=48 \mathrm{~s}, E_{\gamma}=139 \mathrm{keV}, I_{\gamma}=34 \%$ & GeLi & ${ }^{27} \mathrm{Al}(\mathrm{n}, \mathrm{p}){ }^{27} \mathrm{Mg}$ & ref. $[12]$ \\
\hline & activation & $T_{1 / 2}=47.7 \mathrm{~s}$ & HPGe & ${ }^{27} \mathrm{Al}(\mathrm{n}, \alpha)^{24} \mathrm{Na}$ & ref. [13] \\
\hline & activation & $T_{1 / 2}=47.7 \mathrm{~s}, E_{\gamma}=139.7 \mathrm{keV}, I_{\gamma}=39.4 \%$ & HPGe & ${ }^{27} \mathrm{Al}(\mathrm{n}, \mathrm{p}){ }^{27} \mathrm{Mg}$ & ref. [14] \\
\hline \multirow[t]{3}{*}{${ }^{76} \mathrm{Ge}(\mathrm{n}, 2 \mathrm{n}){ }^{75 \mathrm{~g}} \mathrm{Ge}$} & activation & no information & $\mathrm{GeLi}$ & ${ }^{63} \mathrm{Cu}(\mathrm{n}, 2 \mathrm{n}){ }^{62} \mathrm{Cu}$ & ref. $[7]$ \\
\hline & activation & $\begin{array}{l}T_{1 / 2}=82.8 \mathrm{~min}, E_{\gamma}=264.8 \mathrm{keV}\left(I_{\gamma}=11.0 \%\right) \\
E_{\gamma}=199.2 \mathrm{keV}\left(I_{\gamma}=1.4 \%\right)\end{array}$ & GeLi & ${ }^{27} \mathrm{Al}(\mathrm{n}, \mathrm{p}){ }^{27} \mathrm{Mg}$ & ref. [9] \\
\hline & activation & $\begin{array}{l}T_{1 / 2}=82.78 \min , E_{\gamma}=264.0 \mathrm{keV} \\
I_{\gamma}=11.4 \%\end{array}$ & HPGe & ${ }^{27} \mathrm{Al}(\mathrm{n}, \mathrm{p}){ }^{27} \mathrm{Mg}$ & ref. [14] \\
\hline \multirow[t]{10}{*}{${ }^{76} \mathrm{Ge}(\mathrm{n}, 2 \mathrm{n}){ }^{75} \mathrm{Ge}$} & activation & $T_{1 / 2}=82 \min$ & Boron counter & No information & ref. $[24]$ \\
\hline & activation & $T_{1 / 2}=82.2 \min , E_{\gamma}=265 \mathrm{keV}, I_{\gamma}=11.0 \%$ & GeLi & ${ }^{70} \mathrm{Ge}(\mathrm{n}, 2 \mathrm{n}){ }^{69} \mathrm{Ge}$ & ref. $[25]$ \\
\hline & activation & no information & $\mathrm{NaI}$ & $\begin{array}{l}\text { counting the } \\
\text { associated alpha } \\
\text { particles }\end{array}$ & ref. $[26]$ \\
\hline & activation & no information & $\mathrm{Ge}$ & ${ }^{56} \mathrm{Fe}(\mathrm{n}, \mathrm{p}){ }^{56} \mathrm{Mn}$ & ref. [27] \\
\hline & activation & $T_{1 / 2}=1.38 \mathrm{~h}, E_{\gamma}=264.7 \mathrm{keV}, I_{\gamma}=11.3 \%$ & GeLi & ${ }^{27} \mathrm{Al}(\mathrm{n}, \alpha)^{24} \mathrm{Na}$ & ref. [28] \\
\hline & activation & $T_{1 / 2}=81.79 \min$ & $\mathrm{NaI}$ & ${ }^{63} \mathrm{Cu}(\mathrm{n}, 2 \mathrm{n}){ }^{62} \mathrm{Cu}$ & ref. [29] \\
\hline & activation & $T_{1 / 2}=78 \mathrm{~min}$ & GEMUC & ${ }^{56} \mathrm{Fe}(\mathrm{n}, \mathrm{p}){ }^{56} \mathrm{Mn}$ & ref. $[30]$ \\
\hline & activation & no information & HPGe & ${ }^{27} \mathrm{Al}(\mathrm{n}, \alpha){ }^{24} \mathrm{Na}$ & ref. [31] \\
\hline & activation & $T_{1 / 2}=82.78 \mathrm{~min}, E_{\gamma}=264.6 \mathrm{keV}, I_{\gamma}=11.4 \%$ & HPGe & ${ }^{93} \mathrm{Nb}(\mathrm{n}, 2 \mathrm{n}){ }^{92 \mathrm{~m}} \mathrm{Nb}$ & ref. [32] \\
\hline & activation & $T_{1 / 2}=82.78 \min , E_{\gamma}=264.6 \mathrm{keV}, I_{\gamma}=11.4 \%$ & HPGe & ${ }^{27} \mathrm{Al}(\mathrm{n}, \alpha){ }^{24} \mathrm{Na}$ & ref. [33] \\
\hline
\end{tabular}

ture $[7,9,14]$. In the present work, the $264.6 \mathrm{keV}\left(I_{\gamma}=\right.$ $11.4 \%$ ) gamma-ray emitted in the ${ }^{75 \mathrm{~g}} \mathrm{Ge}$ decay was used to deduce the value of the ${ }^{76} \mathrm{Ge}(\mathrm{n}, 2 \mathrm{n})^{75 \mathrm{~g}} \mathrm{Ge}$ reaction cross section. The contribution of the ${ }^{76} \mathrm{Ge}(\mathrm{n}, 2 \mathrm{n})^{75 \mathrm{~m}} \mathrm{Ge}$ reaction via IT (isomeric transition, 99.97\%) was subtracted using eq. (14). Figure 6 shows the excitation function of the ${ }^{76} \mathrm{Ge}(\mathrm{n}, 2 \mathrm{n}){ }^{75 \mathrm{~g}} \mathrm{Ge}$ reaction. Between 13 and $15 \mathrm{MeV}$, the measured data for the ${ }^{76} \mathrm{Ge}(\mathrm{n}, 2 \mathrm{n})^{75 \mathrm{~g}} \mathrm{Ge}$ reaction cross sections can be grouped into two bands which differ by about $80 \%$. The large discrepancies are probably due to the different deducting methods of excited states. Between 13 and $15 \mathrm{MeV}$, the Talys- 1.8 calculations with ldmodels $1-6$ are lower than all the results of papers in the literature $[7,9,14]$, but the TALYS-1.8 calculations with ldmodel 1 (the constant temperature and Fermi gas model) agree very well with our data, whilst the results by Casanova and Sanchez [7], Vanska and Rieppo [9], and Attar et al. [14] are about 60-90\% higher than our data and TALYS-1.8 calculations. For this reaction, other previous authors $[8,10-13]$ only reported cross section values of the excited state and did not give cross section values of the ground state.

\section{$4.3{ }^{76} \mathrm{Ge}(\mathrm{n}, 2 \mathrm{n}){ }^{75} \mathrm{Ge}$ reaction}

The present cross section data for the ${ }^{76} \mathrm{Ge}(\mathrm{n}, 2 \mathrm{n}){ }^{75} \mathrm{Ge}$ reaction are shown in fig. 7 together with the results of the TALYS-1.8 calculation with ldmodels $1,2,3,4,5$, and 6 (given as continuous lines) and earlier measurements $[9$, $12,13,24-33]$. It can be seen that in the 13 to $15 \mathrm{MeV}$ energy range our data are consistent with the results of TALYS-1.8 calculations using ldmodels $1,2,4,5$, and 6 within the experimental uncertainties.

\subsection{Isomeric cross section ratio}

The isomeric cross section ratio $\sigma_{m} / \sigma_{g}$ for the isomeric pair ${ }^{75 m, g}$ Ge produced in the $(n, 2 \mathrm{n})$ reaction on ${ }^{76} \mathrm{Ge}$ was 


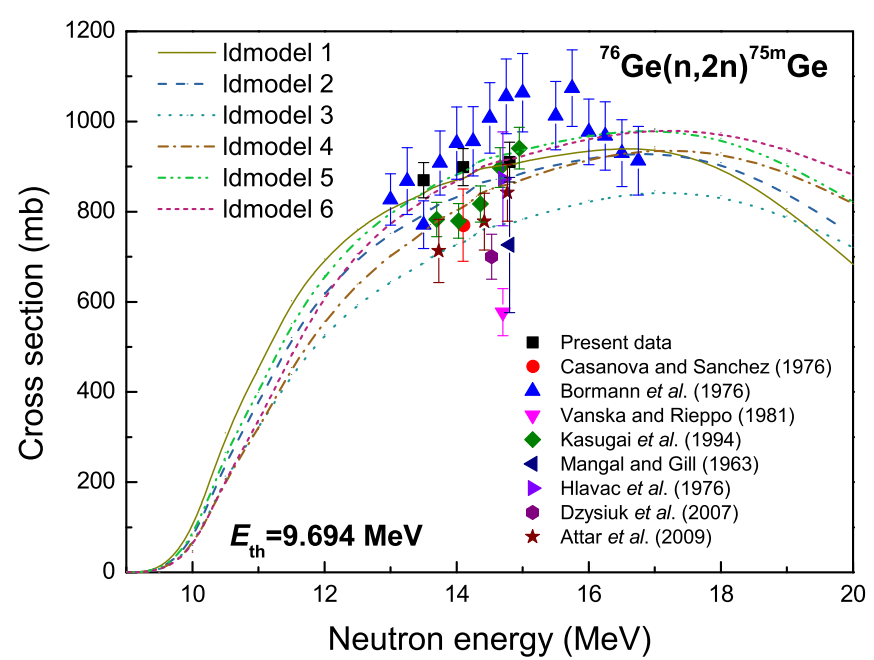

Fig. 5. Excitation function of the ${ }^{76} \mathrm{Ge}(\mathrm{n}, 2 \mathrm{n})^{75 \mathrm{~m}} \mathrm{Ge}$ reaction compared with the present measured data and the literature normalized data.

measured. The obtained cross section ratios are $2.3 \pm 0.2$, $2.4 \pm 0.2$ and $2.4 \pm 0.2$ at neutron energies of $13.5 \pm 0.2$, $14.1 \pm 0.2$, and $14.8 \pm 0.2 \mathrm{MeV}$, respectively. The experimental data and the TALYS-1.8 calculations are shown together in fig. 8. It can be seen that our results agree well with the result of Bhattacharyya et al. [34], and the data from the TALYS-1.8 calculations with ldmodel 1, 2 and 3 .

The isomeric cross section ratio determined in this work has a slightly increasing trend with the increasing neutron energy, suggesting that at higher excitation energies the formation of the high-spin isomer $(7 / 2 \rightarrow 1 / 2)$ is more favored. This trend is similar to that for several other neutron- and charged-particle-induced reactions near thresholds [35-44]. In the range of $13-15 \mathrm{MeV}$, the calculated isomeric cross section ratio shows the same slightly increasing trend for the six ldmodels. Our data and the results of TALYS-1.8 with ldmodels 1,2 , and 3 are somewhat lower than the data of Hlavac et al. [12], Okumura [26], Birn et al. [28], while they are higher than the results of Vanska and Rieppo [9] and Mangal and Gill [11].

\section{Conclusions}

In the present paper, a methodical experimental campaign and TALYS-1.8 code calculations with different level density models have been carried out. Activation cross sections for ${ }^{76} \mathrm{Ge}(\mathrm{n}, 2 \mathrm{n}){ }^{75 \mathrm{~m}} \mathrm{Ge},{ }^{76} \mathrm{Ge}(\mathrm{n}, 2 \mathrm{n})^{75 \mathrm{~g}} \mathrm{Ge}$, and ${ }^{76} \mathrm{Ge}(\mathrm{n}, 2 \mathrm{n}){ }^{75} \mathrm{Ge}$ reactions as well as isomeric cross section ratios for ${ }^{76} \mathrm{Ge}(\mathrm{n}, 2 \mathrm{n})^{75 \mathrm{~m}, \mathrm{~g}} \mathrm{Ge}$ reactions induced by 13.5, $14.1 \mathrm{MeV}$, and $14.8 \mathrm{MeV}$ neutrons have been measured using the latest decay data, and by taking into account the contribution of the metastable state in the case of unstable ground state formation cross section. In order to avoid the effect of low energy neutrons, the near threshold ${ }^{93} \mathrm{Nb}(\mathrm{n}, 2 \mathrm{n}){ }^{92 \mathrm{~m}} \mathrm{Nb}\left(E_{t h}=8.972 \mathrm{MeV}\right)$ monitor reaction was selected, samples were wrapped in a cadmium

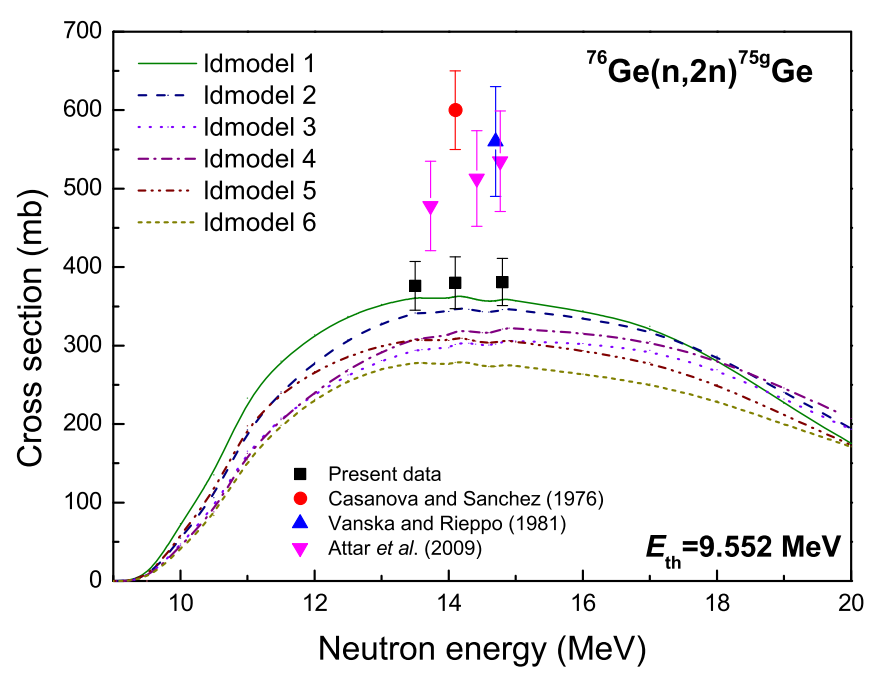

Fig. 6. Excitation function of the ${ }^{76} \mathrm{Ge}(\mathrm{n}, 2 \mathrm{n}){ }^{75 \mathrm{~g}} \mathrm{Ge}$ reaction with the present measured data and the literature data.

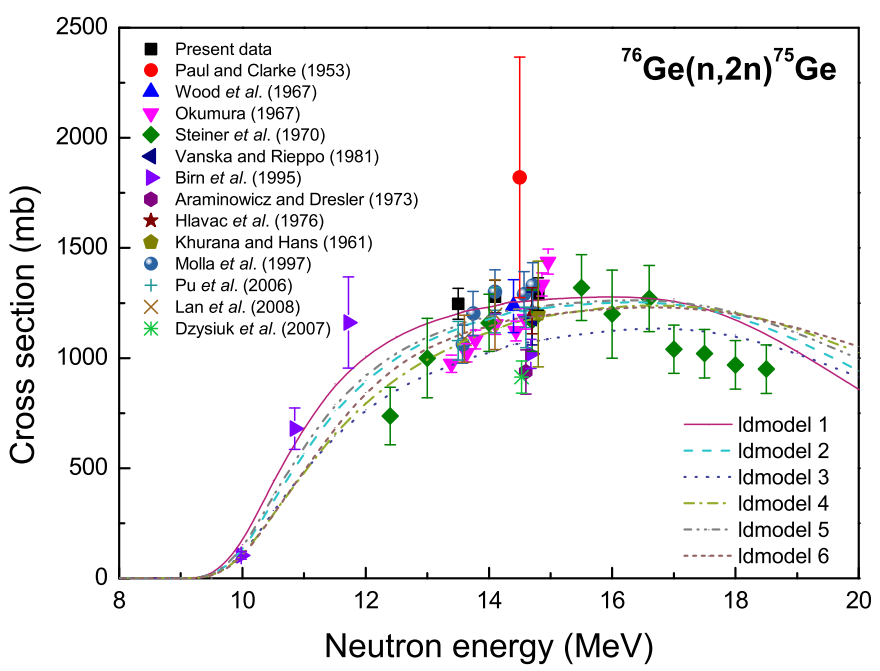

Fig. 7. Excitation function of the ${ }^{76} \mathrm{Ge}(\mathrm{n}, 2 \mathrm{n}){ }^{75} \mathrm{Ge}$ reaction.

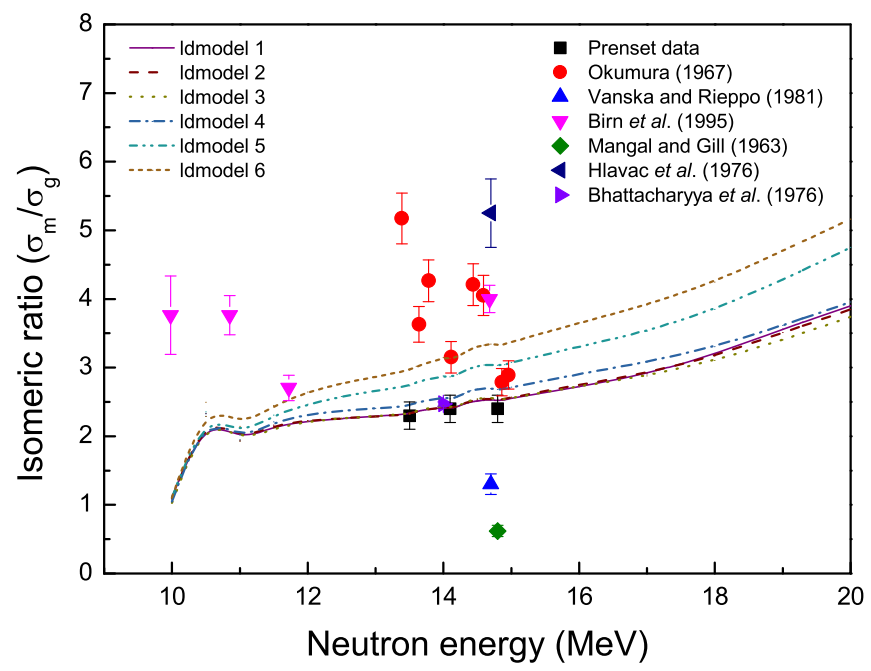

Fig. 8. Cross section ratio of the ${ }^{76} \mathrm{Ge}(\mathrm{n}, 2 \mathrm{n}){ }^{75 \mathrm{~m}} \mathrm{Ge}$ and ${ }^{76} \mathrm{Ge}(\mathrm{n}, 2 \mathrm{n}){ }^{75 \mathrm{~g}} \mathrm{Ge}$ reactions plotted as a function of the neutron energy. 
foil and the new T-Mo target was used. The constant temperature and Fermi gas model (ldmodel 1) is to be preferred for ${ }^{76} \mathrm{Ge}(\mathrm{n}, 2 \mathrm{n})^{75 \mathrm{~m}, \mathrm{~g}} \mathrm{Ge}$ reactions. The results were compared with previous experimental results reported in the literature and theoretical nuclear model calculations computed using TALYS-1.8. A detailed comparison with previously reported cross sections reveals that the discrepancies in the historic data could be due to: 1) the decay data (half-life and ray intensity) used in the determination of the cross sections; 2) the system difference caused by different measuring methods (radiation detector and neutron monitoring method) and experimental conditions (neutron field characteristics); and 3) interfering reactions. The experimental results presented here may be used to more accurately describe the reaction processes and verify statistical model parameters used in their theoretical representation.

We would like to thank the Intense Neutron Generator group at Chinese Academy of Engineering Physics for performing the irradiations. This work was supported by the National Natural Science Foundation of China (Grant No. 11565012).

Open Access This is an open access article distributed under the terms of the Creative Commons Attribution License (http://creativecommons.org/licenses/by/4.0), which permits unrestricted use, distribution, and reproduction in any medium, provided the original work is properly cited.

\section{References}

1. M. Bostan, S.M. Qaim, Phys. Rev. C 49, 266 (1994).

2. CINDA-A: The index to literature and computer files on microscopic neutron data, (International Atomic Energy Agency, Vienna, 2000).

3. V. Mclane, C.L. Dunford, P.F. Rose, Neutron cross sections, Vol. 2 (Academic, New York, 1988).

4. K. Heyde, J.L. Wood, Rev. Mod. Phys. 83, 1467 (2011).

5. Toh et al., Phys. Rev. C 87, 041304(R) (2013).

6. A.S. Davydov, G.F. Filipov, Nucl. Phys. 8, 237 (1958).

7. J.L. Casanova, M.L. Sanchez, An. Fis. Quim. 3, 186 (1976)

8. M. Bormann et al., Progress report, Report from Euratomcountries + Euratom to EANDC, No. 76 (1967) p. 51.

9. R. Vanska, R. Rieppo, Nucl. Instrum. Methods 179, 525 (1981).

10. Y. Kasugai et al., Am. Rev. Respir. Dis. 132, 248 (1994).

11. S.K. Mangal, P.S. Gill, Nucl. Phys. 49, 510 (1963).

12. S. Hlavac et al., Acta Phys. Slov. 26, 64 (1976).

13. N.R. Dzysiuk et al., Yad. Fiz. Energ. 8, 68 (2007).

14. F.M.D. Attar et al., Nucl. Phys. A 828, 253 (2009).

15. F. Zhou et al., Phys. Rev. C 80, 054615 (2009).

16. J. Luo et al., Appl. Radiat. Isot. 66, 1920 (2008).
17. J. Luo et al., Radiochim. Acta 101, 607 (2013).

18. Evaluated Nuclear Structure Data File (ENSDF), http://www.nndc.bnl.gov/ensdf/.

19. M. Wagner et al., Physik Daten-Physics Data, Evaluation of Cross Sections for 14 important Neutron Dosimetry Reactions, Fachinformationszentrum Karlsruhe, Gesellschaft für wissenschaftlich-technische Information mbH, Federal Republic of Germany. No.13-5 (1990).

20. J.H. Hubbell, S.M. Seltzer, Tables of $x$-ray mass attenuation coefficients and mass energy-absorption coefficients from $1 \mathrm{keV}$ to $20 \mathrm{MeV}$ for elements $Z=1$ to 92 and 48 additional substances of dosimetric interest (1996) http://physics.nist.gov/PhysRefData/XrayMassCoef/ tab3.html.

21. A. Koning, S. Hilaire, S. Goriely, TALYS-1.8, A Nuclear Reaction Program, NRG-1755 ZG Petten, The Netherlands (2015) http://www.talys.eu.

22. J.R. Taylor, An Introduction to Uncertainty Analysis (University Science Books, Mill Valley, California, 1982).

23. RIPL-2 Reference Input Parameter Library, IAEA, A-1400 Vienna, IAEA-NDS, http://www-nds . iaea.org/RIPL-2/.

24. E.B. Paul, R.L. Clarke, Can. J. Phys. 31, 267 (1953).

25. R.E. Wood et al., Phys. Rev. 154, 1108 (1967).

26. S. Okumura, Nucl. Phys. A 93, 74 (1967).

27. E. Steiner et al., Helv. Phys. Acta 43, 17 (1970).

28. I.G. Birn et al., Phys. Rev. C 52, 2546 (1995).

29. J. Araminowicz, J. Dresler, Investigation of the (n,2n) reaction with $14.6 \mathrm{MeV}$ neutrons, Progress Report, Inst. Badan Jadr. (Nucl. Res.), Swierk+Warsaw, Repts., No. 1464 (1973) p.14.

30. C.S. Khurana, H.S. Hans, Nucl. Phys. 28, 560 (1961).

31. N.I. Molla et al., in Conference on Nuclear Data for Science and Technology, Trieste 1997, Vol. 1 (SIF, 1997) p.517.

32. Z. $\mathrm{Pu}$ et al., High. Energy Phys. Nucl. Phys. 30, 1171 (2006) in Chinese.

33. C. Lan et al., Ann. Nucl. Energy 35, 2105 (2008).

34. P. Bhattacharyya et al., Decay of the $83 \mathrm{~min} \mathrm{Ge-75}$ and energy levels and gamma-transitions in As-75, in Nuclear Physics and Solid State Physics Symposium, Ahmedabad, Vol. 2, Part 19B (Department of Atomic Energy, Bombay, India, 1976) p. 316.

35. S.M. Qaim, A. Mushtaq, M. Uhl, Phys. Rev. C 38, 645 (1988).

36. N.I. Molla, S.M. Qaim, M. Uhl, Phys. Rev. C 42, 1540 (1990).

37. S.M. Qaim et al., Phys. Rev. C 42, 363 (1990).

38. S. Sudár, F. Szelecsényi, S.M. Qaim, Phys. Rev. C 48, 3115 (1993).

39. F. Cserpák et al., Phys. Rev. C 49, 1525 (1994).

40. I.G. Birn et al., Phys. Rev. C 52, 2546 (1995).

41. S. Sudár, S.M. Qaim, Phys. Rev. C 53, 2885 (1996).

42. C.D. Nesaraja, S. Sudár, S.M. Qaim, Phys. Rev. C 68, 024603 (2003).

43. S. Sudár, S.M. Qaim, Phys. Rev. C 73, 034613 (2006).

44. M. Al-Abyad et al., Phys. Rev. C 73, 064608 (2006). 